\title{
Alumina reinforced eucryptite ceramics: very low thermal expansion material with improved mechanical properties.
}

Olga García-Moreno ${ }^{1}$, Amparo Borrell ${ }^{1}$, Birgit Bittmann ${ }^{3}$, Adolfo Fernández ${ }^{2}$ and Ramón Torrecillas ${ }^{1}$

1. Centro de Investigación en Nanomateriales y Nanotecnología (CINN)

Principado de Asturias - Consejo Superior de Investigaciones Científicas (CSIC) Universidad de Oviedo (UO). Spain.

Parque Tecnológico de Asturias, 33428 Llanera, (Asturias), Spain.

2. Fundación ITMA, Parque Tecnológico de Asturias, 33428, Llanera, (Asturias), Spain

3. Institut fuer Verbundwerkstoffe GmbH, Erwin Schroedinger Str. Geb. 58, 67663 Kaiserslautern.

Abstract. Composite materials formed by a LAS matrix reinforced with second phases are promising materials in many applications where better mechanical properties than those corresponding to conventional low thermal expansion coefficient materials are required. In this study we will show the capability of the design of a LAS-alumina submicron composite. The main scope of this work is to test the sinterability of the composites and to design a composition for a very low thermal expansion submicron composite. For this purpose, Taimei alumina (TM-DAR) powders and an ad-hoc synthesized $\beta$ - eucryptite phase were used to fabricate the composite. XRD phase compositions and microstructures are discussed together with data from dilatometries in a wide temperature range. The results obtained show the possibility of designing a submicron composite with a very low thermal expansion coefficient and improved mechanical properties that can be used in oxidizing conditions. 
Keywords. Submicron composites, eucryptite, coefficient of thermal expansion, alumina.

\section{Introduction.}

Materials with a very low coefficient of thermal expansion (CTE) are of great interest because of their many different applications, from cookware to aerospace applications. There are two different approaches in order to obtain this kind of material: a monolithic material with very low CTE can be used, or a material with a very low CTE can be designed, combining phases with positive and negative CTE [1]. The second approach opens a wider range of possibilities in comparison with the use of monolithic materials. Apart from designing materials for a very low CTE, tailoring of materials can be used for other specific functional or structural properties.

The lithium aluminosilicate family (LAS) is the most studied system to prepare materials with very low CTE properties. Eucryptite and spodumene are the most used and studied phases with these characteristics[2, 3]. It is well known [4-6] that sintering of these materials to obtain dense ceramic bodies is quite complicated. This is due to their narrow range of sintering temperatures and the easy formation of a vitreous phase, as the invariant points in this system are found at relatively low temperatures. By contrast, they are usually employed as glass-ceramic materials [7-10]. Therefore, by conventional methods of pressureless natural sintering, the ceramic materials thus obtained have low mechanical properties and Young's modulus.

The fabrication of submicron composites is proposed here as a solution to this problem, using sintering methods that can lead to high relative densities with little or no glassy phase. Composites in the system LAS-alumina can be found in the literature $[11,12]$. 
Nevertheless, in these cases they deal with an alumina matrix with dispersed spodumene. In those composites, the CTE value is low compared to that of monolithic alumina, but it is still far from zero values. Moreover, lowering the CTE is done to the detriment of the mechanical properties of pure alumina.

In this study, the capability of a sintering method for the fabrication of dense composites of submicron alumina dispersed in a LAS matrix with a tailored composition for an ultra low CTE value of the composite will be shown. Firstly, the capability of the design of LAS-alumina submicron composites will be shown. Then, it is necessary to control the sinterability of the composites and to design a composition for a very low thermal expansion. For these purposes, Taimei alumina (TM-DAR) powders and an ad-hoc synthesized $\beta$ - eucryptite phase were used to fabricate the composite. XRD phase compositions and microstructures are discussed together with data from dilatometries in a wide temperature range. The spark plasma sintering (SPS) of composites, with an alumina reinforced LAS matrix, is also studied and proposed as a solution to obtain relatively high and improved mechanical properties compared to the LAS ceramics obtained by conventional methods. The sintering capability of this composite by SPS methods and the comparison of the mechanical properties of the composites are presented.

\section{Experimental procedures.}

\section{Materials.}

$\beta$ - eucryptite s. s. powders with a composition between eucryptite and spodumene were synthesized for this study as it was described in a previous work (see [13] for details). The chemical composition is shown in Figure 1 and corresponds to a $\mathrm{Li}_{2} \mathrm{O}: \mathrm{Al}_{2} \mathrm{O}_{3}: \mathrm{SiO}_{2}$ 
relation of 1:1.01:3.11. Although other LAS compositions such as those described in [13] were also tested, the main results were obtained using this composition.

\section{FIGURE 1}

The LAS powders thus synthesized are composed of $\beta$ - eucryptite s. s. and traces of quartz and spodumene as shown in the difractogram of Figure 2. The powders have a mean grain size of $1 \mu \mathrm{m}$ and were characterized for their CTE behavior as described in a previous paper [13]. CTE values of the samples were used to design composites with very low expansion in a wide temperature range.

\section{FIGURE 2}

Composites of the aforementioned LAS matrix and a second phase of dispersed submicron alumina were formulated according to the compositions shown in Table 1 and projected in the diagram of Figure 1. Composites TLAS1, 2, 3, 4 and 5 have the same LAS matrix composition mixed with alumina Taimei TM-Dar. Other LAS compositions were used to test compatibility with alumina and are shown in Table 2.

The composites formulated as described above were fabricated by mixtures of LAS and alumina powders by attrition milling in ethanol. Synthesized LAS powders were mixed with Taimei (TM-DAR) $\alpha$-alumina, with a mean grain size of $160 \mathrm{~nm}$. The slurry thus obtained was dried and sieved under $63 \mu \mathrm{m}$. An additional mixture was prepared using a different alumina powder in order to observe the influence of the alumina precursor on the chemical compatibility. For mixture SLAS10, Ceralox SPA-0.5 Sasol $\alpha$-alumina, with an average grain size of $440 \mathrm{~nm}$ was used.

Grain sizes of both mixtures with different alumina precursors were estimated by laser diffraction in a Coulter LS 13320 apparatus, with a measurement range of $40 \mathrm{~nm}-2000$ $\mu \mathrm{m}$. Results are shown in Figure 3. Similar particle size distribution is observed for both 
samples showing bimodal distributions. The peak around 1-2 microns is due to LAS grains, whereas the submicronic size peak corresponds to alumina grains. It can be seen how Taimei alumina mixtures (TLAS5) have a wider grain size distribution starting from $60 \mathrm{~nm}$.

\section{FIGURE 3}

\section{Sintering and Characterization.}

The powders were pressed to form green bodies by cold isostatic pressing at $200 \mathrm{MPa}$ for natural sintering experiments and uniaxially pressed in $20 \mathrm{~mm}$ diameter graphite dies for Spark Plasma Sintering experiments.

In the first case a conventional furnace was used for the sintering process of the green bodies in air at atmospheric pressure. The sintering temperature was chosen after studying the dynamic sintering curves of samples with different alumina content in a Netzsch DIL402C dilatometer.

For the Spark Plasma experiments a HPD25/1 from FCT apparatus was used. The SPS apparatus generates electrical power which is delivered through the die in rapid pulses. A vacuum was maintained in the apparatus during the sintering process. The external force applied to the die was $16 \mathrm{kN}$. The samples were fired at a heating rate of $100 \mathrm{~K} / \mathrm{min}$ to temperatures between 1100 and $1200{ }^{\circ} \mathrm{C}$ with a short dwell time of 2 minutes, and free cooling.

$\mathrm{X}$-ray diffraction (XRD) analysis was used to identify the phases present in the powdered and sintered materials. XRD patterns were obtained using a diffractometer (Model D5000, Siemens, Karlsruhe, Germany) with $\mathrm{CuK \alpha}$ radiation operating at $40 \mathrm{kV}$ and $30 \mathrm{~mA}(\lambda=0.15418 \mathrm{~nm})$. Patterns were recorded over the goniometer range of $10^{\circ}-$ $65^{\circ}$ with a step size of $0.02^{\circ}$ and a counting time of $1 \mathrm{~s}$ per step. The levels of the $\beta$ - 
eucryptite and glass phases in the ceramic materials were determined by XRD Rietveld phase composition analysis. Rietveld refinement calculations were done with MAUD program [14]. Absolute levels of the glass phase for the $\beta$-eucryptite ceramics were derived using a Rietveld procedure, with Aldrich $99.99 \% \mathrm{CaF}_{2}$ as external standard material. The crystal structure model used for the $\beta$ - eucryptite was that corresponding to ICDS code 24896 , and 82707 for fluorite. The glassy phase content was determined indirectly by the difference between the total phase levels and $100 \%$.

The apparent densities of resulting materials were measured by the Archimedes method and the real density by He pycnometry. For conventional sintering, with low theoretical density samples, fracture surfaces were observed for microstructure. In the case of close to theoretical density samples (composites with the lower alumina content), samples were cut, polished, thermally etched and Au-coated to observe the microstructures. For the SPS sintered samples, with near theoretical density samples, the microstructures have been obtained from polished and chemically etched surfaces. Both SEM (Zeiss DSM) 950 and Field Emission-Scanning Electron Microscopy (FE-SEM, (Zeiss Ultraplus)) were used to obtain the images of the microstructures. The fracture strength of materials was tested by the four point bending and biaxial tests in polished surface finished bars and discs, employing the equations of Kirstein and Woolley [15], Vitman and Pukh [16], and the ASTM standard specification F394-78 [17], using INSTRON (model 8562) equipment. The coefficient of thermal expansion was checked in a Netzsch DIL402C between -150 and $450{ }^{\circ} \mathrm{C}$.

\section{Results and Discussion.}

Pressureless conventional sintering. 
Dynamic sintering of three selected composites in the LAS-alumina system was performed. The sintering curves are shown in Figure 4. These curves show densification of the green bodies with 10 (TLAS1), 50 (TLAS2) and 90 (TLAS3) wt.\% LAS up to $1400{ }^{\circ} \mathrm{C}$. The composite with highest LAS content (TLAS3) melts at a temperature close to $1400{ }^{\circ} \mathrm{C}$. Then, it was decided to sinter the composites at $1350{ }^{\circ} \mathrm{C}$ for all the compositions described above for comparison. The temperature was raised at $5 \mathrm{~K} / \mathrm{min}$ and maintained at $1350^{\circ} \mathrm{C}$ for 4 hours. Cooling was controlled at $5 \mathrm{~K} / \mathrm{min}$ down to 900 ${ }^{\circ} \mathrm{C}$. The results are exposed in Table 3 .

\section{FIGURE 4}

The phase composition of sintered samples was studied by XRD. In Figure 5, it can be observed that no reaction occurred between the LAS phase and alumina, avoiding the formation of third phases such as mullite or lithium aluminate, as could be expected from the $\mathrm{Li}_{2} \mathrm{O}-\mathrm{Al}_{2} \mathrm{O}_{3}-\mathrm{SiO}_{2}$ equilibrium phase diagrams [18-20]. This was confirmed for all the composites tested, either with different LAS-alumina contents or for different LAS compositions synthesized ad hoc (Table 2). Moreover, an additional LAS-alumina composite was tested using a different alumina powder and once more no reaction between alumina and the LAS phase was observed, at least for the formation of third phases, including glassy phase. Quantification of constituent phases was performed for two sintered samples: TLAS5-1350 ${ }^{\circ} \mathrm{C}$ and SLAS10-1350 ${ }^{\circ} \mathrm{C}$, both with 84.35 wt.\% LAS, with Taimei and Sasol alumina powders respectively. Rietveld refinement and quantification gave negligible amounts of glass phase (below $2 \%$ ).

\section{FIGURE 5}

Densities and microstructure. 
As described in Table 3, pressureless sintering lead to density values which are in some cases far from $100 \%$ theoretical density, especially when the alumina content is $\geq 50 \%$ (TLAS 1 and TLAS2). When the LAS content is $\geq 80 \%$, composites with density $>90 \%$ t.d. can be obtained. Concerning the influence of the alumina precursor, when the same composition, (84.35 wt.\% LAS), and the same sintering temperature are used, the composite prepared with Sasol alumina (SLAS10) has slightly higher density than composite TLAS5, with Taimei alumina. The main differences between both alumina precursors are grain size and specific surface. Sasol alumina grain size distribution (Figure 3b) seems to be the more suitable for obtaining denser composites, although in both cases, the final density is $>98 \%$ t.d.

Microstructures observed by SEM images show porosity in most of the samples. Figure 6 illustrates some examples of these microstructures in fracture and polished surfaces for the samples sintered by conventional methods for 10,50 and $84.35 \mathrm{wt} \%$ LAS composites. The dispersion of the nanoparticles in the LAS matrix can be observed in Fig. $6 \mathrm{~d}$ in a polished surface of a close to theoretical dense sample. The alumina submicron particles are embedded in the micrometric LAS particles and are distributed homogeneously both as intra- and intergranular particles, indicating growth of the $\beta$ eucryptite crystals during sintering. Residual porosity can also be observed in these microphotographs, especially in Fig. 6c, in agreement with the relative density values obtained.

\section{FIGURE 6}

Spark plasma sintering (SPS).

Spark Plasma Sintering of the composites TLAS5 and SLAS10, both with the same composition (84.35 wt.\% LAS) but with different alumina precursor, was performed. The SPS was used in order to obtain better final densities in the composites and also to 
lower the sintering temperatures. Results for density and CTE values are described in Table 4. It was proved the strong effect of maximum temperature selected in SPS tests on densification of this type of materials. It can de observed how the density raise from $80 \%$ t.d. to $100 \%$ t.d. by increasing $100{ }^{\circ} \mathrm{C}$ the final temperature. Moreover, the temperature used for full densification $\left(1200^{\circ} \mathrm{C}\right)$ is considerably lower than corresponding to pressureless sintering $\left(1350^{\circ} \mathrm{C}\right)$ even if in the later case there is residual porosity.

Lowering the sintering temperatures would affect the amount of glassy phase formed during sintering and this would have a positive effect on the final mechanical properties of the materials, as described below. Quantitative phase estimation performed in the samples sintered by conventional methods show the initial formation of glass phase, with amounts below $2 \%$. The glass phase contents are null for the SPS sintered samples which sintering temperature was $150{ }^{\circ} \mathrm{C}$ below, and the total time for SPS cycle is around 30 minutes. Furthermore, theoretical density values were reached thanks to the pressure applied during heating.

Microstructures of the SPS sintered samples are shown in Figure 7 for 10, 50 and 84.35 wt $\%$ LAS composites. The samples with 10 and $50 \mathrm{wt} . \%$ LAS are chemically etched with Borax producing a borate glaze at $900{ }^{\circ} \mathrm{C}$ [21]. This can be shown in Figure $7 \mathrm{a}$ and $7 \mathrm{~b}$, were the alumina grains are revealed while the LAS phase has been dissolved. This microstructures can be compared with the ones shown in Figures $6 \mathrm{a}$ and $6 \mathrm{~b}$ for conventional sintering in fracture surfaces. The submicron nature of the raw alumina is preserved. For greater LAS content, $84.35 \mathrm{wt}$ \% LAS, the chemical etching was made using the vapors of a heated HF dissolution in water (28\%), in order to reveal the microstructure. This is shown in Figure 7c for the composite prepared with the Taimei alumina raw material and in $7 \mathrm{~d}$ for the Sasol alumina one. It can be observed the initial 
submicron alumina size preserved after sintering and the differences in grain size of both precursor. For both samples, dense bodies were obtained although some residual porosity can be observed in the Sasol alumina composite, which is possibly magnified after the chemical etching. In any case there has been observed any kind of glassy phase (which dissolution would be greatly favored) in these sintered samples.

\section{Thermal and Mechanical Properties.}

The coefficient of thermal expansion of some of the sintered samples is pictured in Table 3 and 4 for different alumina - LAS proportions and different sintering methods. Elongation versus temperature curves are shown in Figure 8, for the composites described in Table 1 with Taimei alumina, for a wide range of LAS-alumina compositions from $100 \mathrm{wt} . \%$ alumina to $100 \mathrm{wt} . \%$ LAS. It can be observed how the CTE can be adjusted between the values of alumina and LAS pure phases, mixing different proportions to obtain the desired final CTE in the composite. The lack of reaction between alumina and LAS phase allows predicting the final phase composition and therefore, it is possible to design different properties in the material such as its CTE.

\section{FIGURE 8}

Fracture strength values were measured for the alumina-LAS composite with the closest to zero CTE values, i.e. compositions TLAS5 and SLAS10, for both sintering methods: conventional and SPS. Results are summarized in Table 5.

For both composites, TLAS5 and SLAS10, the strength values obtained by SPS methods are better than those obtained by conventional pressureless sintering. There is a close relationship between strength and microstructure. Comparison between microstructures shown in Figures 6a and 7 gives us an idea of how the residual porosity 
present in conventional sintered samples may affect the mechanical properties. In addition, for similar density values obtained by conventional and SPS sintering methods, the glass proportion, if any, is lower in the SPSed samples as it was estimated by Rietveld quantifications, that is due to the lower sintering temperature employed. Both features, glass content and remaining porosity, are drastically decreased using SPS sintering, giving place to better of values for the same composition.

The resulting strength values in these composites are in the range of aluminaspodumene composites in the literature [12] for samples with much higher alumina proportions (85\% alumina sintered at $1600{ }^{\circ} \mathrm{C}$ gave $178 \mathrm{MPa}$ ). Other studies [11], with LAS proportions in the range of the compositions tested in this study, gave even lower strength values (148 MPa). The sintering temperatures of those studies are higher than the melting point of LAS phases (around $1400^{\circ} \mathrm{C}$ ) and the presence of glass phase may affect the mechanical properties of those composites. Glass-ceramics in [22] have a maximum LAS phase content of $45 \mathrm{wt} . \%$ (with a CTE value around $4 \times 10^{-6} \mathrm{~K}^{-1}$ ) and the flexure strength values obtained for compositions four times richer in alumina than our compositions are half the strength values obtained in our study. The relatively low sintering temperatures needed to obtain theoretical density values in our composites are essential, as they make the strength values increase due to the low proportion of glassy phase formed during sintering. Moreover, in both cases, the CTE values of the composites obtained in the present study are closer to zero and in a wide temperature range, including cryogenic conditions. This adjustment of the CTE of the composites has been successful for both sintering methods and very close to zero values (See Table 3) were obtained for the 84.35 wt.\% LAS composite.

All these features can be combined for designing an ultra low CTE composite. This had already been achieved by using glass-ceramic materials such as Zerodur [7] or even 
pure LAS ceramics [13] and the NZP family [23-25], but the strength values of the LAS-alumina composites presented here fulfill more demanding requirements for the final application of these materials. The LAS-alumina composites proposed here open the opportunity of tailoring the CTE of materials with improved properties. It is important to note that materials with close to zero CTE value commonly used for different applications are glass-ceramic materials with poor mechanical properties or reinforced with carbides such as $\mathrm{SiC}$ or $\mathrm{TiC}$. This kind of reinforcements limits the use of these materials to non-oxidizing atmospheres. The materials presented in this work have improved mechanical properties, tailorable CTE and stability in oxidizing conditions.

\section{Conclusions.}

The LAS- alumina composites proposed in this study have shown the capability of the simple fabrication of ultra low and tailored CTE materials with improved mechanical properties. The formation of third phases was avoided opening the possibility of tuning the CTE value.

The composites comprising $15.65 \mathrm{wt} . \%$ alumina and $84.35 \mathrm{wt} . \% \beta$ - eucryptite gave the closest to zero CTE value for a wide temperature range.

These composites can be sintered by conventional methods obtaining high density bodies with relatively good mechanical properties. By Spark Plasma Sintering of the same powders they are obtained theoretical density bodies with higher strength values at lower temperatures.

\section{References.}


1. García-Moreno, O., Fernández, A., and Torrecillas, R., Conventional sintering of LAS-SiC nanocomposites with very low thermal expansion coefficient. $J$. Eur. Ceram. Soc., 2010. 30(15), 3219-25.

2. García Verduch, A. and Moya, J.S. Reaction at low temperatures between kaolin and lithium carbonate. in International Clay Conference. 1972.

3. Moya, J.S., García Verduch, A., and Hortal, M., Thermal expansion of betaeucriptite solid solutions. Trans. J. Br. Ceram. Soc., 1974. 73(6), 177-8.

4. Roy, R., Agrawal, D.K., and McKinstry, H.A., Very Low Thermal-Expansion Coefficient Materials. Annu. Rev. Mater. Sci., 1989. 19, 59-81.

5. Chen, J.C. and Sheu, G.J., Method of producing lithium aluminosilicate ceramics, US, 6764565B2, 2004.

6. Mandal, S., Chakrabarti, S., Das, S., and Ghatak, S., Sintering characteristics of in situ formed low expansion ceramics from a powder precursor in the form of hydroxy hydrogel. Ceram. Int., 2004a. 30(8), 2147-55.

7. Bach, H., Low thermal expansion glass ceramics. 1995, Berlin: Springer-Verlag. 223.

8. Barbieri, L., Leonelli, C., Manfredini, T., Siligardi, C., Corradi, A.B., Mustarelli, P., and Tomasi, C., Nucleation and Crystallization of a Lithium Aluminosilicate Glass. J. Am. Ceram. Soc., 1997. 80 (12), 3077-83.

9. Riello, P., Bucella, S., Zamengo, L., Anselmi-Tamburini, U., Francini, R., Pietrantoni, S., and Munir, Z.A., Erbium-doped LAS glass ceramics prepared by spark plasma sintering (SPS). J. Eur. Ceram. Soc., 2006. 26(15), 3301-6.

10. Tkalčce, E., Šenija, D., Dondur, V., and Petranović, N., Influence of Dopants on Nucleation and Growth of High-Quartz Solid Solution in Lithium Aluminosilicate Glass. J. Am. Ceram. Soc., 1992. 75(7), 1958-63.

11. Bayuseno, A.P., Latella, B.A., and O'Connor, B.H., Resistance of aluminaspodumene ceramics to thermal shock. J. Am. Ceram. Soc., 1999. 82(4), 819-24.

12. Awaad, M., Mörtel, H., and Naga, S.M., Densification, mechanical and microstructure properties of $\beta$-spodumene-alumina composites. J. Mater. Sci.: Mater. Electron., 2005. 16(6), 377-81.

13. García-Moreno, O., Fernández, A., Khainakov, S., and Torrecillas, R., Negative thermal expansion of lithium aluminosilicate ceramics at cryogenic temperatures. Scripta Mater., 2010. 63, 170-3.

14. Lutterotti, L., Total pattern fitting for the combined size-strain-stress-texture determination in thin film diffraction. Nuclear Instruments and Methods in Physics Research, Section B: Beam Interactions with Materials and Atoms, 2010. 268(3-4), 334-40.

15. Kirstein, A.F. and Woolley, R.M., Symmetrical bending of thin circular elastic plates on equally spaced point supports. J. Res. Natl. Bur. Stand. C, 1967. 71, 110.

16. Vitman, F.F. and Pukh, V.P., A method for determining the strength of sheet glass. Zavod. Lab, 1963. 29 863-7.

17. F394-78, A.S., STM Annual Book of Standards, in STM Annual Book of Standards, Materials, A.S.f.T.a., Editor. 1996: Philadelphia, PA. 466-90.

18. Roy, R., Roy, D.M., and Osborn, E.F., Compositional and stability relationships among the Lithium Aluminosilicates: Eucryptite, Spodumene and Petalite. $J$. Am. Ceram. Soc., 1950. 33(5), 152-9.

19. Kim, K.H. and Hummel, F.A., Studies in Lithium Oxide Systems: IX, Li2OAl2O3-TiO2. J. Am. Ceram. Soc., 1960. 43(12), 611-4. 
20. Galakhov, F.Y., Alumina region of ternary aluminosilicate systems Communication 4. The system Li2O-Al2O3-SiO2. Bulletin of the Academy of Sciences of the USSR Division of Chemical Science, 1960. 8(4), 550-6.

21. Scott, C., Hill, S., and Hosmer, K., ALUMINA MICROSTRUCTURAL SAMPLE PREPARATION USING A BORATE GLAZE. J. Am. Ceram. Soc., 1986. 69(3).

22. Geodakyan, J.A., Kostanyan, A.K., Geodakyan, K.J., Sagatelyan, S.T., and Petrosyan, B.V. The influence of beta-eucryptite glassceramics on the structure and main properties of alumna ceramics. in 28th International Conference on Advanced Ceramics and Composites. 2004. Cocoa Beach, FL.

23. Roy, R., Synthesizing new materials to specification. Solid State Ionics, 1989. 32-33(Part 1), 3-22.

24. Breval, E., McKinstry, H.A., and Agrawal, D.K., New [NZP] materials for protection coatings. Tailoring of thermal expansion. J. Mater. Sci., 2000. 35(13), 3359-64.

25. Orlova, A., Koryttzeva, A., Lipatova, Y., Zharinova, M., Trubach, I., Evseeva, Y., Buchirina, N., Kazantsev, G., Samoilov, S., and Beskrovny, A., New NZPbased phosphates with low and controlled thermal expansion. J. Mater. Sci., 2005. 40(9), 2741-3.

Acknowledgments. We would like to thank Prof. Salvador de Aza and Prof. Serafín Moya for the thorough discussion of $\mathrm{LAS}-\mathrm{Al}_{2} \mathrm{O}_{3}$ solid state compatibility and comments on a first version of the manuscript. The authors greatly appreciate the support of the EU for the IP- Nanoker NMP3-CT-2005-515784 in the frame of the 6th Framework Program. García-Moreno is working for CSIC under a JAE-Doc contract co- funded by the ESF. A. Borrell is working with financial support of National Plan Project MAT2006-01783 under FPI contract.

Figure Footnotes

Figure 1. LAS composition and alumina - LAS composites represented in the phase diagram after Roy [18].

Figure 2. Difractogram of the synthesized LAS powders. Peaks are marked E for $\beta$ eucryptite, $\mathrm{S}$ for spodumene and $\mathrm{Q}$ for quartz.

Figure 3. Grain size distribution of (a) TLAS5 and (b) SLAS10 powder samples.

Figure 4. Dynamic sintering of LAS - alumina composites with 10 (TLAS1), 50 (TLAS2) and 90 (TLAS3) wt.\% LAS.

Figure 5. Difractograms of the composite TLAS5. TLAS5 is the starting powder XRD pattern, $1350{ }^{\circ} \mathrm{C}$ corresponds to the sample sintered at that temperature by conventional 
sintering and $1200{ }^{\circ} \mathrm{C}$ SPS corresponds to the sample sintered by SPS at that temperature. Only corundum peaks are marked (A), the rest of the peaks correspond to $\beta$ - eucryptite (see Figure 2).

Figure 6. FE-SEM secondary electron images of fracture surfaces of a) TLAS1, b) TLAS2 and c) TLAS5 composites pressureless sintered. Magnification is x12500. Microstructure d) corresponds to sample TLAS5 in polished surface after thermal etching in a SEM secondary electron micrograph.

Figure 7. FE-SEM secondary electron images of polished surfaces of samples sintered by SPS. a) TLAS1 and b) TLAS2. The chemical etching with borate glaze dissolved all the LAS grains (dissolved grains marked with a discontinuous white line). Greater LAS content, for both alumina precursors are shown in c) for Taimei alumina TLAS5 and d) for Sasol alumina SLAS10.

Figure 8. Thermal expansion of the LAS-alumina composites showing the range of CTE within which materials with any CTE, including zero, can be made. 


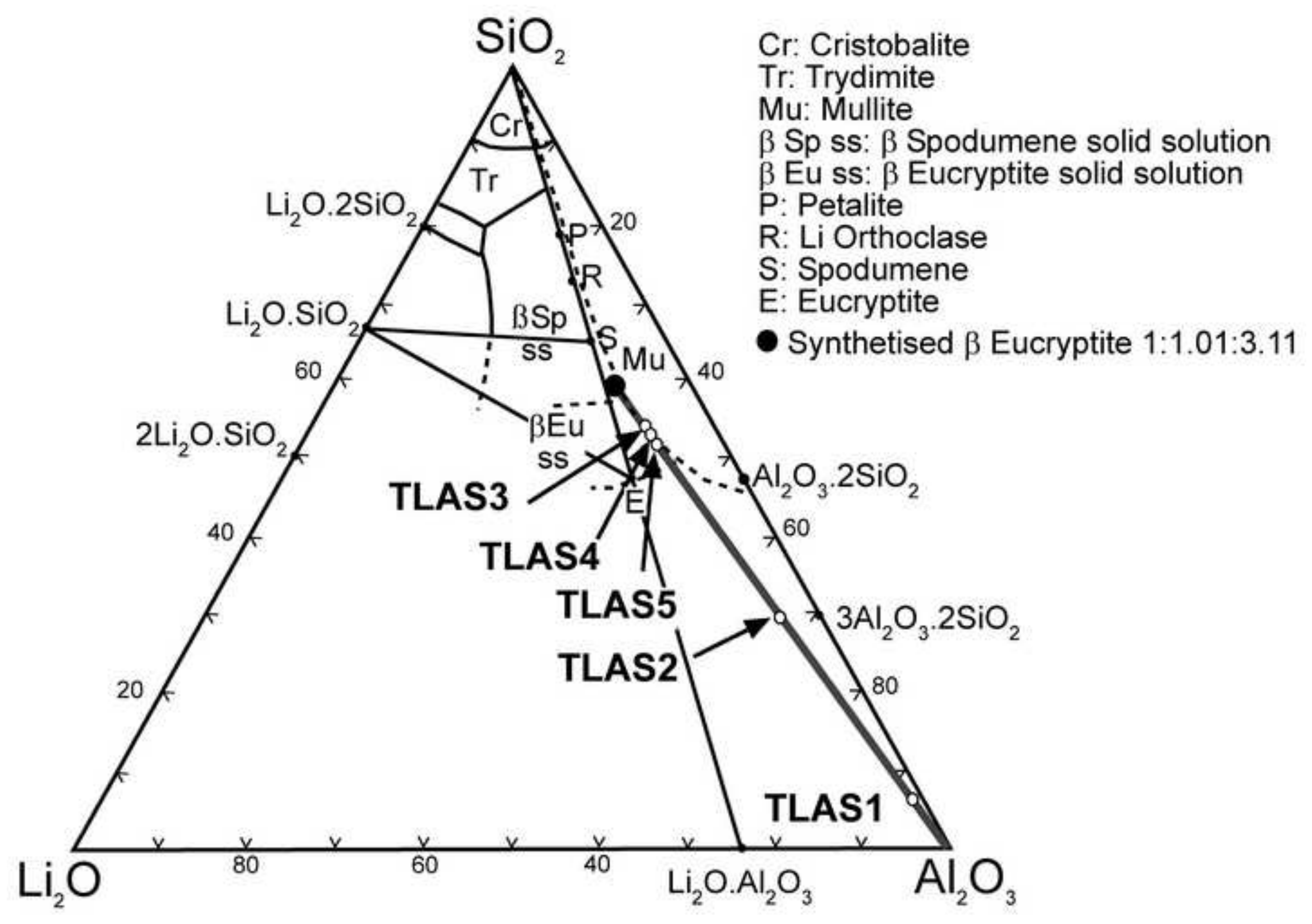


Figure 2

Click here to download high resolution image

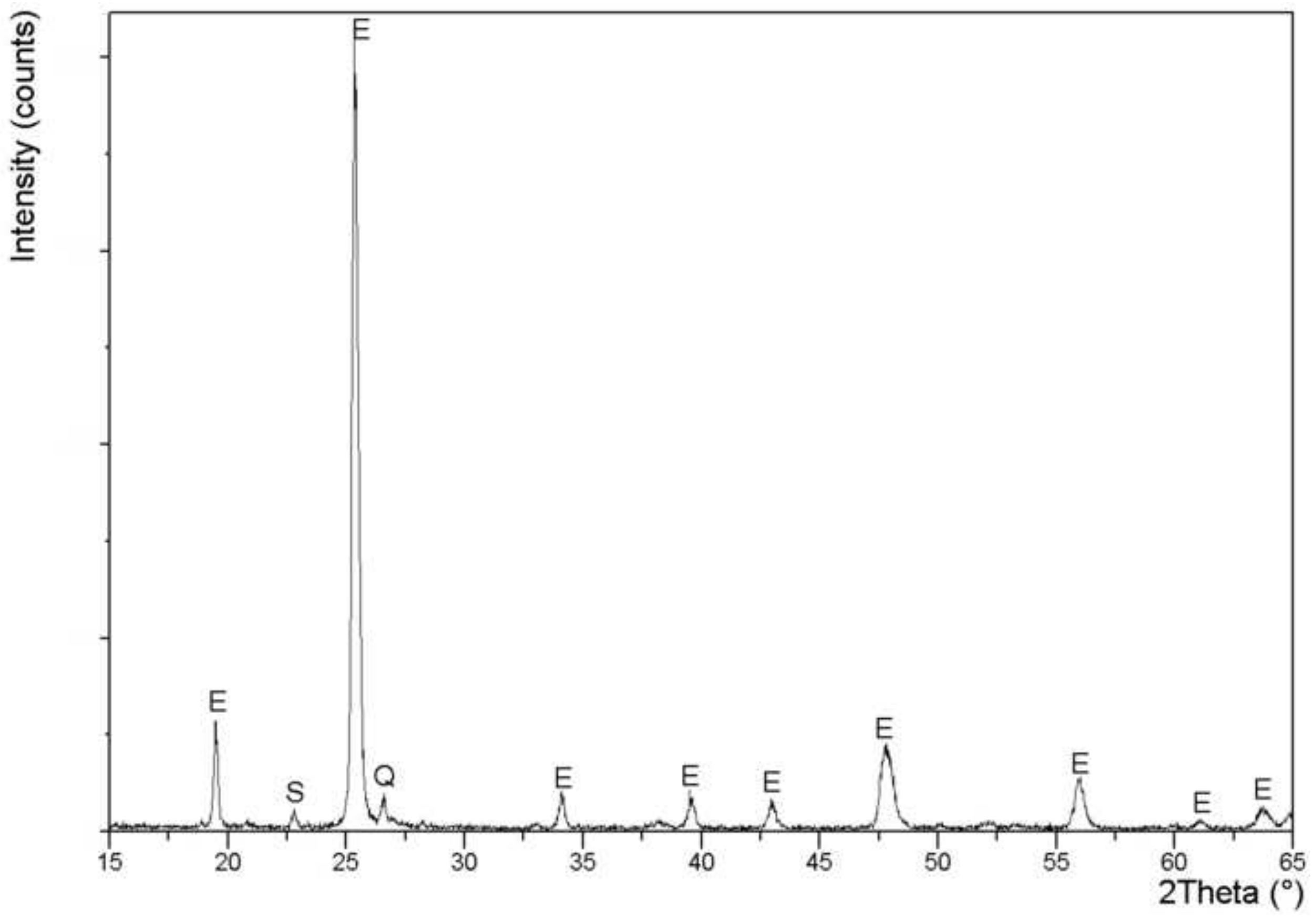


Click here to download high resolution image
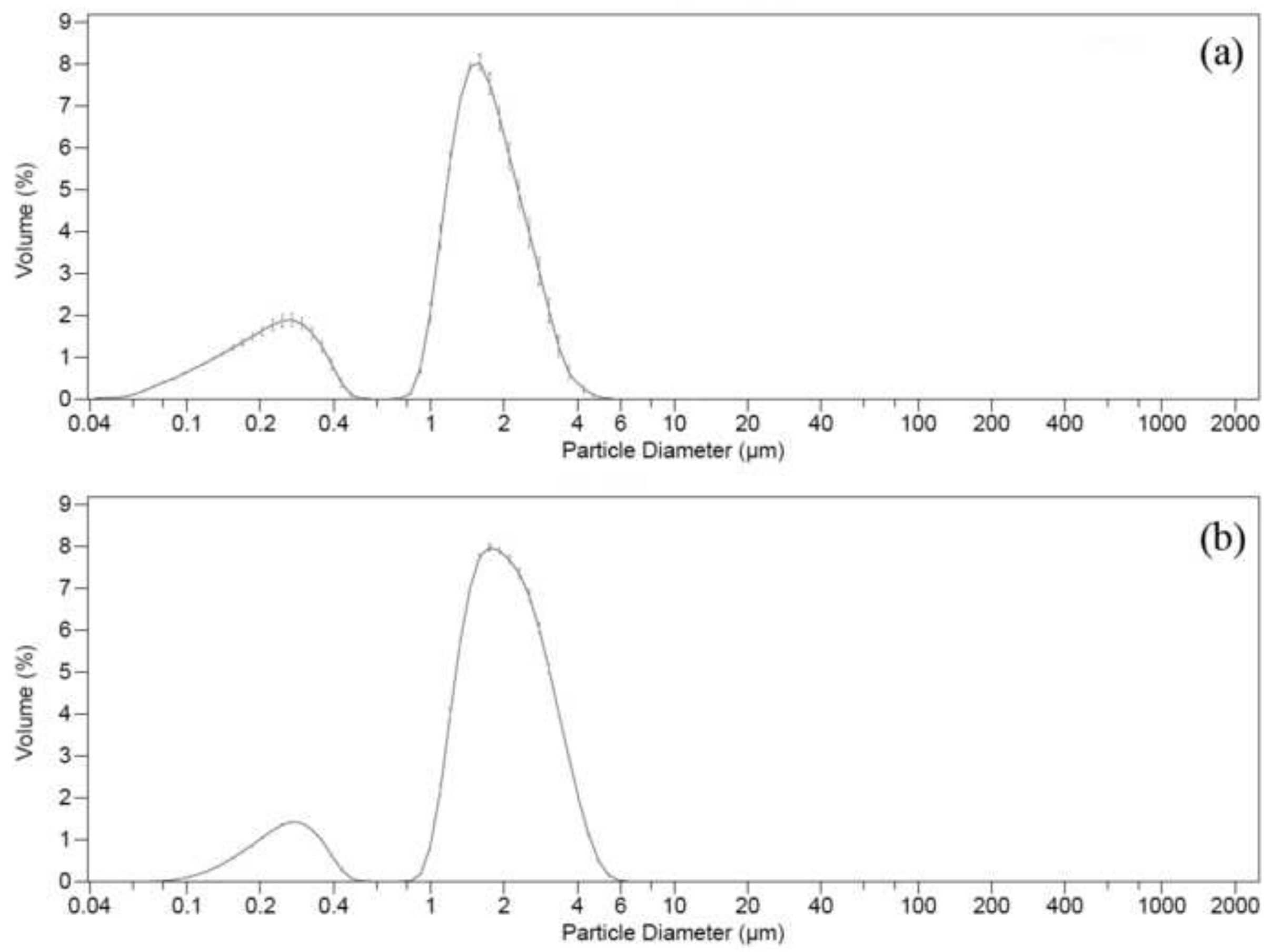


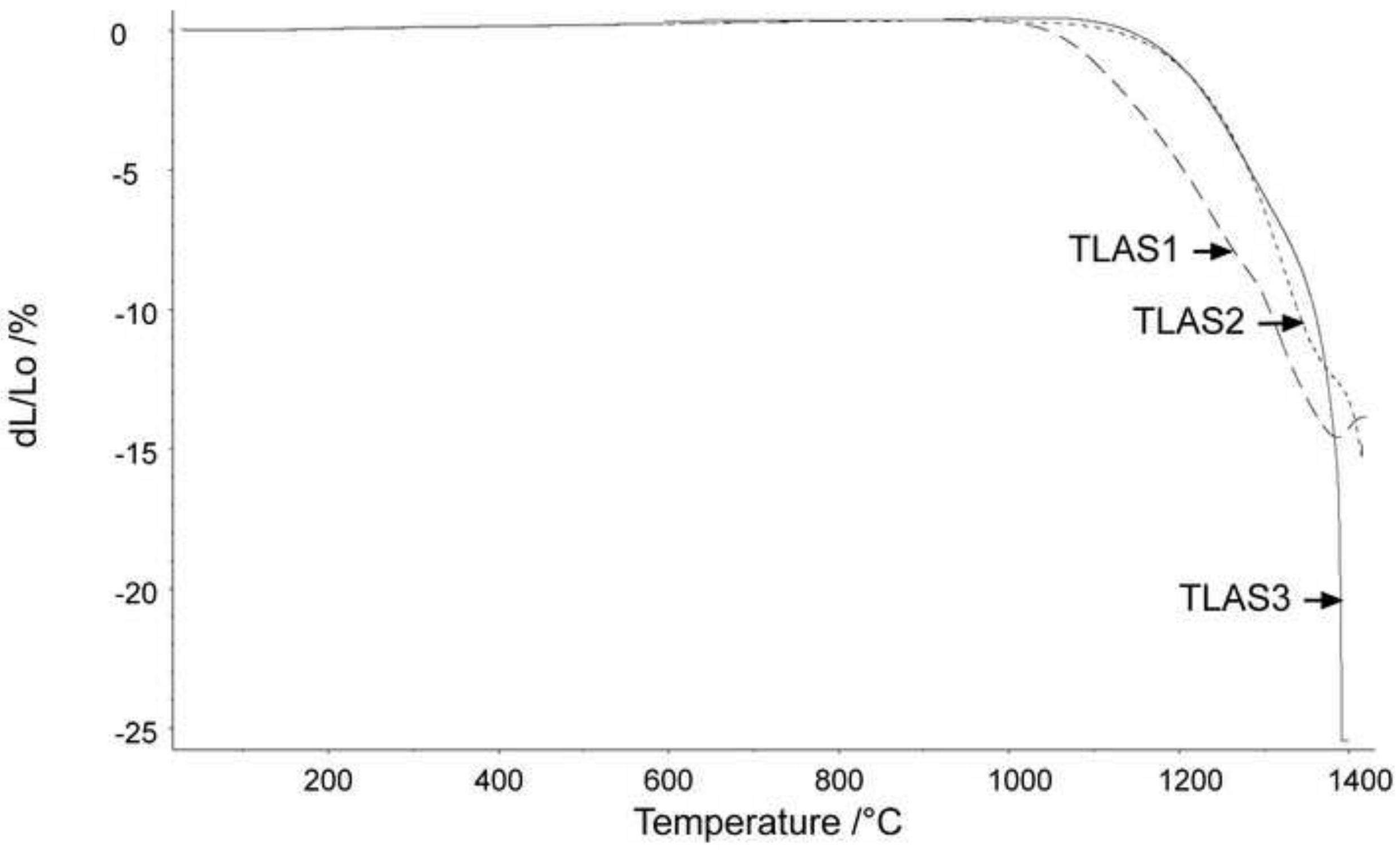




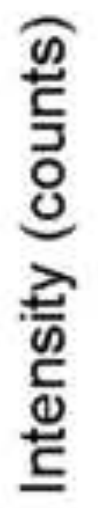

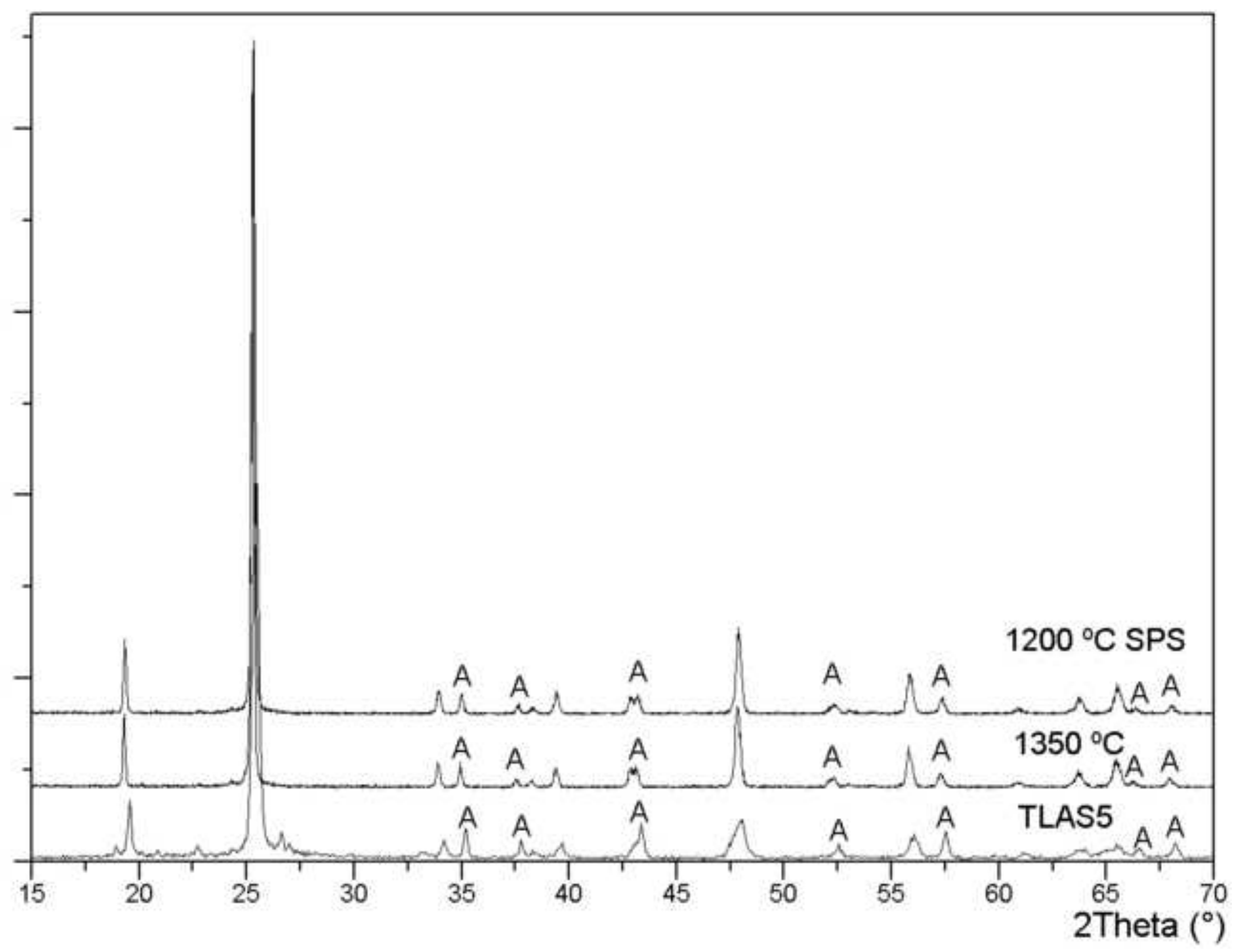


Click here to download high resolution image
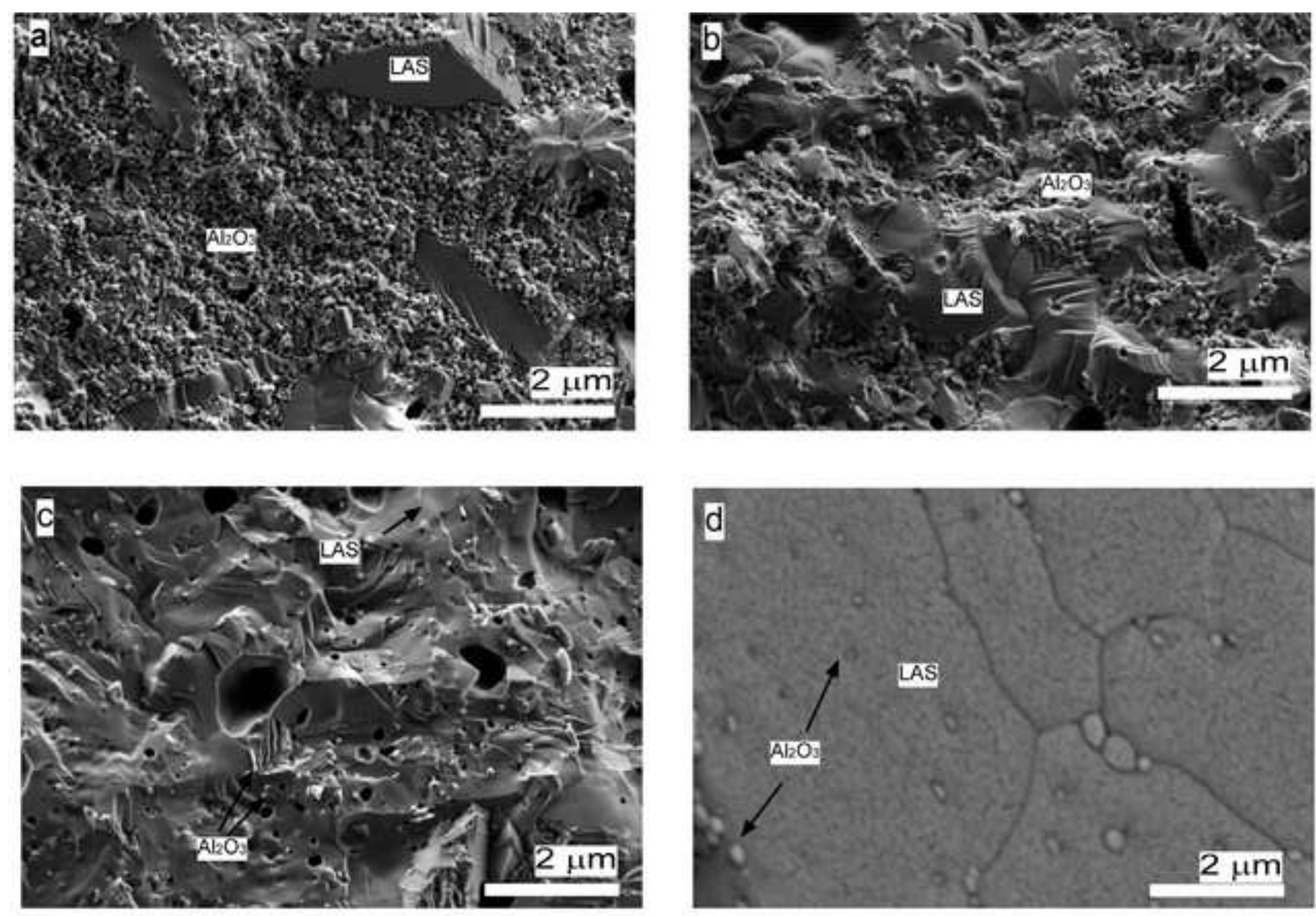
Click here to download high resolution image
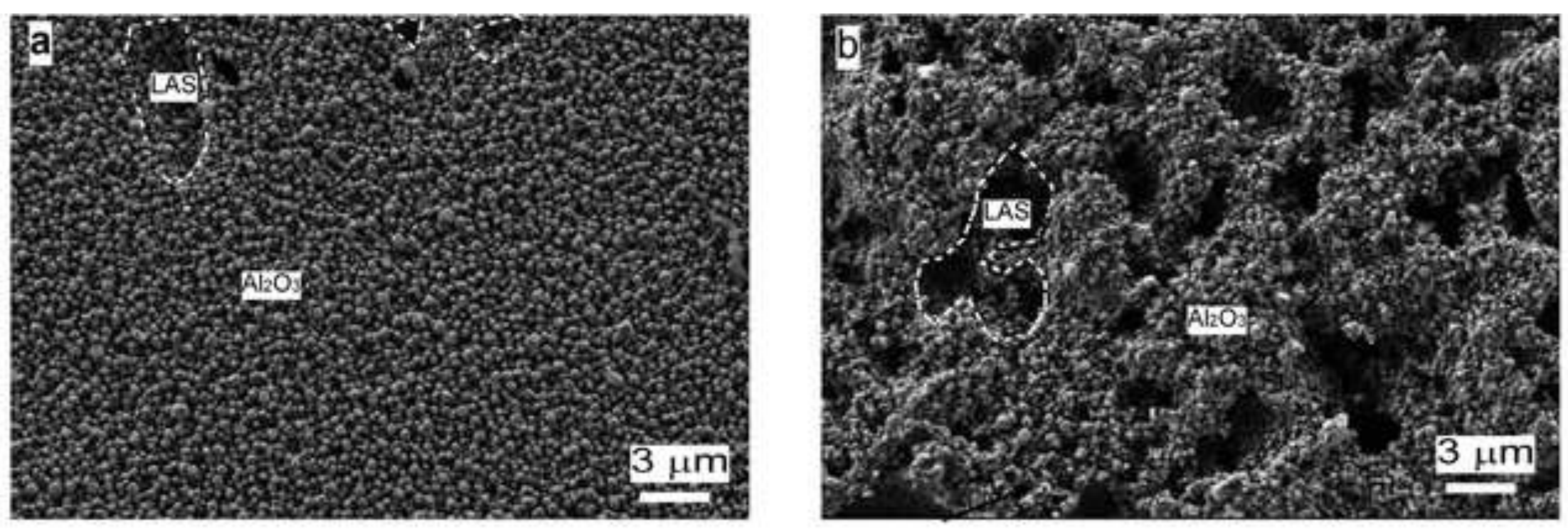

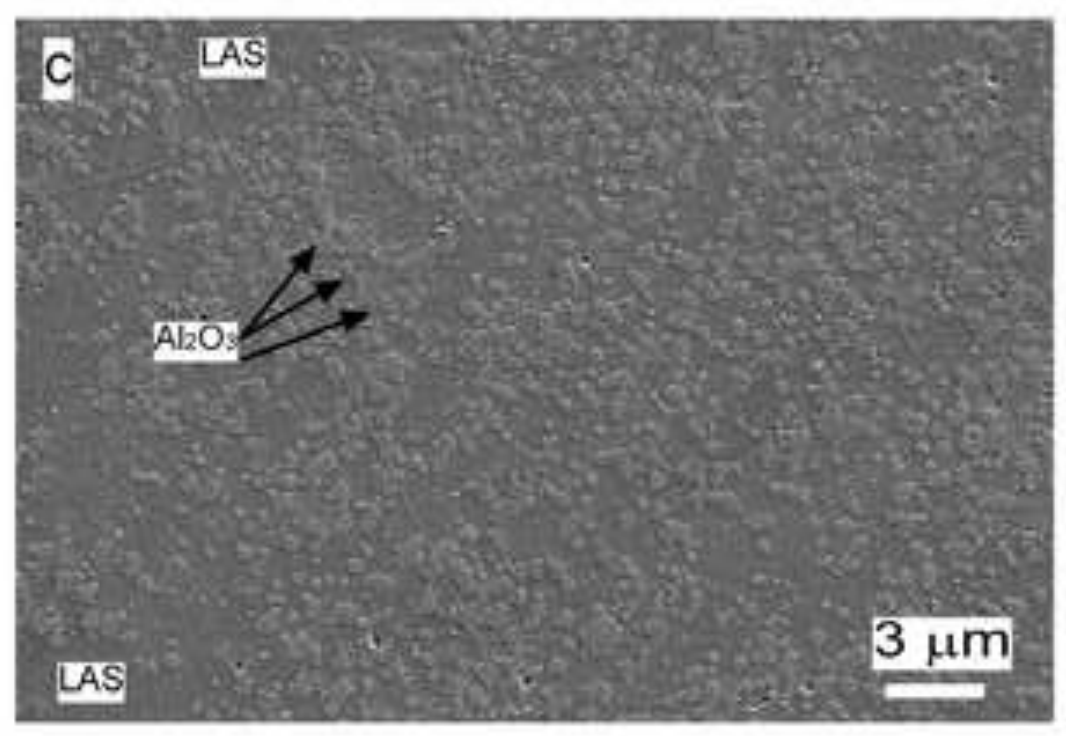

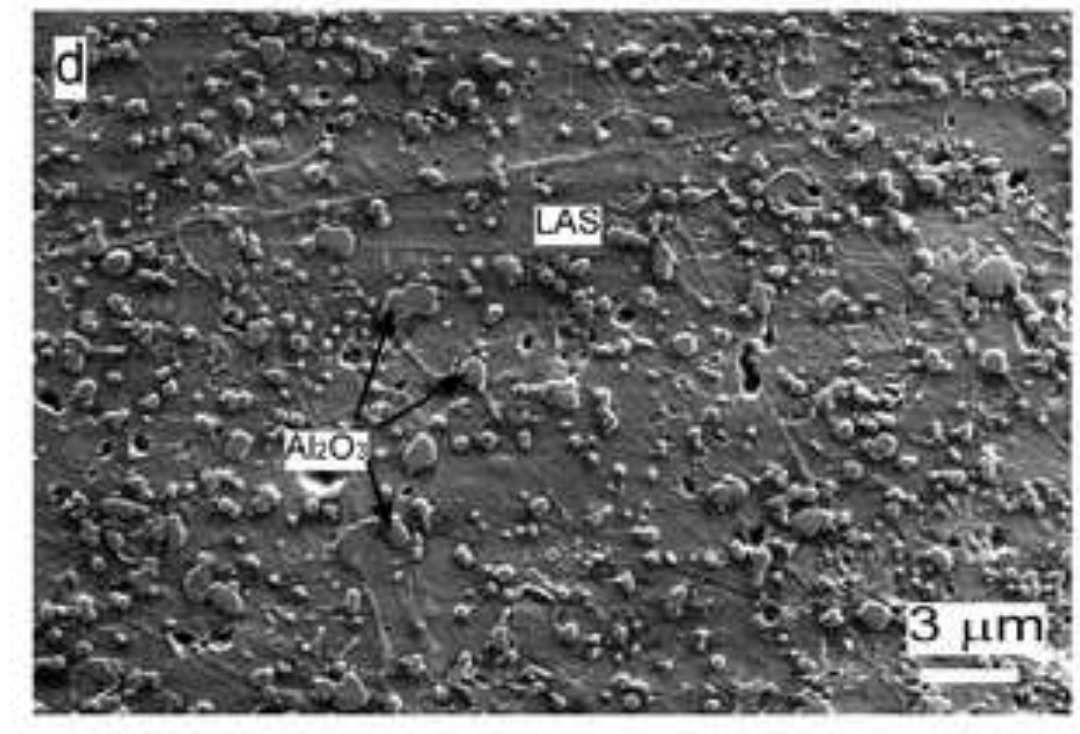




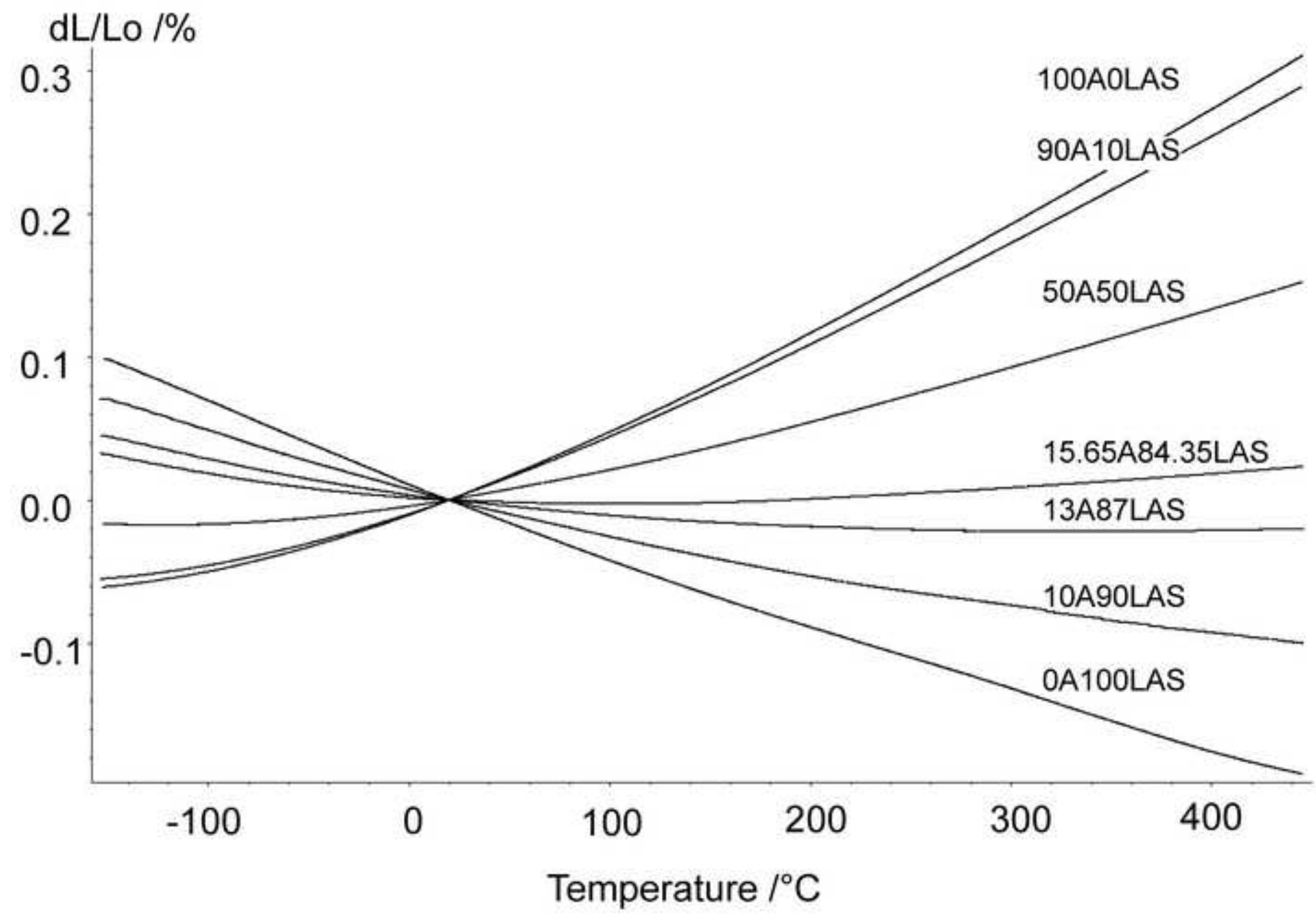


Table 1. Composition of the LAS-Alumina composites with LAS 1:1.01:3.11. Same nomenclature as in [10].

\begin{tabular}{lcccc}
\hline Composition & $\mathrm{Al}_{2} \mathrm{O}_{3}$ & Wt.\% & LAS & Wt.\% \\
\hline TLAS1 & Taimei & 90 & $1: 1.01: 3.11$ (LAS4) & 10 \\
TLAS2 & Taimei & 50 & $1: 1.01: 3.11$ (LAS4) & 50 \\
TLAS5 & Taimei & 15.65 & $1: 1.01: 3.11$ (LAS4) & 84.35 \\
TLAS4 & Taimei & 13 & $1: 1.01: 3.11$ (LAS4) & 87 \\
TLAS3 & Taimei & 10 & $1: 1.01: 3.11$ (LAS4) & 90 \\
\hline SLAS10 & Sasol & 15.65 & $1: 1.01: 3.11$ (LAS4) & 84.35 \\
\hline
\end{tabular}


Table 2. Composition of other the LAS-Alumina composites with different LAS compositions. Same nomenclature as in [10].

\begin{tabular}{lcccc}
\hline Composition & $\mathrm{Al}_{2} \mathrm{O}_{3}$ & Wt.\% & LAS & Wt.\% \\
\hline TLAS6 & Taimei & 8 & $1: 0.91: 3.48($ LAS14) & 92 \\
\hline TLAS7 & Taimei & 18.5 & $1: 1.17: 3.04($ LAS15) & 81.5 \\
\hline TLAS8 & Taimei & 8 & $1: 1.17: 2.49($ LAS8) & 92 \\
\hline
\end{tabular}


Table 3. Experimental results of the conventionally sintered samples. Composite TLAS5 (84.35 \% LAS) gives near zero CTE values in a wider temperature range and good density values and has been chosen for further sintering studies.

\begin{tabular}{|c|c|c|c|c|c|}
\hline $\begin{array}{l}\text { Sintering } \\
\text { method }\end{array}$ & Composition & $\mathbf{T}$ & Density & $\begin{array}{l}\text { CTE -150 } \\
\text { to } 450 \text { ㅇ } \\
\left({ }^{\star} 10-6\right)\end{array}$ & $\begin{array}{l}\text { CTE } 25 \\
\text { to } 450 \text { - } \\
C\left(^{*} 10-6\right)\end{array}$ \\
\hline Conventional & TLAS1 & $1350^{\circ} \mathrm{C}$ & $<80.0 \%$ & 5.77 & 6.81 \\
\hline Conventional & TLAS2 & $1350^{\circ} \mathrm{C}$ & $<80.0 \%$ & 2.84 & 3.60 \\
\hline Conventional & TLAS3 & $1350^{\circ} \mathrm{C}$ & $95.4 \%$ & -0.58 & 0.04 \\
\hline Conventional & TLAS5 & $1350^{\circ} \mathrm{C}$ & $98.8 \%$ & -0.14 & 0.56 \\
\hline Conventional & TLAS4 & $1350^{\circ} \mathrm{C}$ & $93.7 \%$ & -1.08 & 0.46 \\
\hline Conventional & SLAS10 & $1350^{\circ} \mathrm{C}$ & $99.7 \%$ & -0.13 & 0.43 \\
\hline
\end{tabular}


Table 4. SPS sintered samples results.

\begin{tabular}{|c|c|c|c|c|c|}
\hline $\begin{array}{l}\text { Sintering } \\
\text { method }\end{array}$ & Composition & $\mathbf{T}$ & Density & $\begin{array}{l}\text { CTE -150 } \\
\text { to } 450 \text { ㅇ } \\
\left({ }^{*} 10-6\right)\end{array}$ & 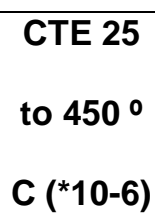 \\
\hline SPS & TLAS5 & $1100^{\circ} \mathrm{C}$ & $80.7 \%$ & -0.36 & 0.24 \\
\hline SPS & TLAS5 & $1150^{\circ} \mathrm{C}$ & $92.4 \%$ & -0.14 & 0.57 \\
\hline SPS & TLAS5 & $1200^{\circ} \mathrm{C}$ & $100.0 \%$ & -0.15 & -0.52 \\
\hline SPS & SLAS10 & $1200^{\circ} \mathrm{C}$ & $100.0 \%$ & -0.24 & 0.44 \\
\hline
\end{tabular}


Table 5. Strength values of sintered samples by SPS and conventional pressureless sintering methods

\begin{tabular}{|l|l|l|l|}
\hline $\begin{array}{l}\text { Sintering } \\
\text { method }\end{array}$ & Composition & Temperature & of (MPa) \\
\hline SPS & TLAS5 & $1100^{\circ} \mathrm{C}$ & $74.2 \pm 4.3$ \\
\hline SPS & TLAS5 & $1150^{\circ} \mathrm{C}$ & $142.1 \pm 6.3$ \\
\hline SPS & TLAS5 & $1200^{\circ} \mathrm{C}$ & $163.8 \pm 6.1$ \\
\hline Conventional & TLAS5 & $1350^{\circ} \mathrm{C}$ & $138.5 \pm 3.7$ \\
\hline SPS & SLAS10 & $1200^{\circ} \mathrm{C}$ & $165.9 \pm 5.4$ \\
\hline Conventional & SLAS10 & $1350^{\circ} \mathrm{C}$ & $140.2 \pm 6.1$ \\
\hline
\end{tabular}

